\title{
BUSINESS RISK MANAGEMENT BASED ON A SERVICE PORTFOLIO APPROACH FOR AN EQUIPMENT-PROVIDING SERVICE
}

\author{
Tadasuke Nakagawa ${ }^{1}$, Shigeyuki Tani ${ }^{1}$, \\ Chizuko Yasunobu ${ }^{1}$ and Norihisa Komoda ${ }^{2}$ \\ ${ }^{1}$ Hitachi, Ltd., Systems Development Laboratory; Hitachi System Plaza Shinkawasaki, 890. \\ Kashimada, Saiwai-ku, Kawasaki-shi, Kanagawa-ken, 212-8567 Japan \\ ${ }^{2}$ Osaka Universitv, 2-1. Yamadaoka, Suita-shi, Osaka-fu, 565-087I Japan
}

\begin{abstract}
In recent years. companies have become reluctant to accept the risk associated with investment in equipment. Therefore, equipment-providing services, where an outside provider owns the equipment and collects fees for its use from the user, have become increasingly popular because they reduce the users' investment risks. In exchange for receiving these fees, an equipment provider takes on part of each user's operating risk. For such a service to be profitable, though, the supplier must be able to accurately determine the appropriate risk and measure how much of this risk it is accepting instead of the user. It is critical that the equipment provider have an effective means to control the risk and understand its potential negative effect.
\end{abstract}

Keywords: cquipment-providing services; risk: price

\section{Introduction}

In recent years, the uncertainty surrounding corporate management has risen for several reasons, and investment in an enterprise and equipment is increasingly risky in terms of future profitability. As a result, many businesses now prefer to keep such investment at arm's length by obtaining equipment through equipment-providing services. In this service, an equipment provider makes the initial investment, and the provider's profits depend on how each user operates the equipment. In this way, the provider also takes on some of the user's operating risk. For an equipment provider to operate profitably, it must be able to accurately determine the amount of risk related to such equipment provision and price its services accordingly. To enable this, we have developed a profitability simulator for equipment-providing services . Conventionally, con- 


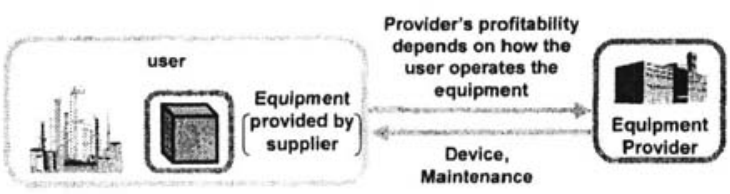

Figure 1. Business Model of an Equipment-providing Service

tracts have been priced according to the amount of risk associated with each contract, and it has been assumed that although a provider and user can share the operating risk this risk cannot be decreased.

In this research, we show that equipment-providers can reduce their overall risk through diversification since they serve users in various types of industry and different regions of operation. Since diversification reduces the overall risk, an equipment provider can offer such a service at a lower price which reflects the risk reduction made possible by a portfolio approach rather than taking an individual-contract perspective.

The rest of this paper is organized as follows. Chapter 2 describes the riskmanagement method conventionally used by an equipment-providing service and the problem with this method. In Chapter 3, we explain the portfolio effect and how it should be reflected in service pricing. In Chapter 4, we validate the effectiveness of this approach. We conclude in Chapter 5.

\section{Business Risk Management for Equipment-Providing Services}

\section{Business Risk Management on a Contract Basis}

The business model of equipment-providing services, where an equipmentprovider rather than a user owns the equipment, is outlined in Figure 1. Equipment-providers supply various types of equipment such as information technology (IT) hardware or energy-saving equipment and charge a fee which depends on, for example, the amount of equipment used, the usage time, or the effect. However, since the provider's profitability depends on how the user operates the equipment, an important characteristic of an equipment-providing service is that the user and the equipment provider share the uncertainty (risk) regarding future returns on investment. For an equipment provider to avoid taking on excessive risk and ensure long-term profitability, the provider must accurately determine the amount of risk it accepts for each service offer and price the offer accordingly. Our approach to this problem is to consider first the risk with regard to fluctuations. To accurately determine the amount of risk, we develop an equipment-provider profit simulator. And, we use the size of the profit-prediction range to define the amount of risk. 


\section{Problem with Conventional Methods}

The methods conventionally used have a certain limitation, as follows.

1 An equipment provider typically has service contracts with many users, and the number of risks which a service supplier is exposed to will expand as the number of users rises. To run such a service safely, the provider must be able to determine the total amount of risk.

2 Conventionally, a provider prices such a service by determining the potential costs of the risks associated with each service contract assuming that these risks are shared between the user and the provider and that the amount of inherent risk cannot be reduced.

\section{Risk Management through a Service Portfolio Approach}

\section{Quantification of the Service Portfolio Effect}

When the total risk taken on by an equipment provider is conventionally calculated, the overall risk is considered to be a simple sum of the amount of risk associated with each service contract. In this research, we quantify the total amount of risk based on portfolio theory. A portfolio is a combination of various assets owned by an investor. By combining assets with different risk characteristics with regard to profitability, portfolio investment allows an investor to reduce risk through diversification. An equipment provider holds a portfolio of service contracts, and each contract can be considered an asset. We think that the risk associated with each contract can be reduced by combining many contracts whose profitability will depend on different factors, such as industry type and region of operations. The amount of risk reduction achieved through such diversification can be quantified.

The overall risk of a portfolio is computed using the variance and covariance of the returns generated by the contracts held in the portfolio. In this way, a linear relationship between the portfolio return and effective risk assessment can be established. The standard deviation $S\left(R_{p}\right)$ is expressed (1) where $R_{p}$ is portfolio, $\gamma_{i}$ is the investment rate of asset $i, \sigma_{i i}$ denotes the variance of the return from asset $i$, and $\sigma_{i j}$ denotes the covariance between the returns of asset $i$ and asset $j$.

$$
S\left(R_{p}\right)=\sqrt{\sum_{i} \sum_{j} \gamma_{i} \gamma_{j} \sigma_{i j}}
$$

As for investment in stocks, Eq. (1) is used when asset is distributed to each brand. However, since the service itself can not be distributed in an equipment- 
providing service, we can assume that $\gamma=1(i=1,2, \ldots, N)$. That is, $S\left(R_{p}\right)$ is expressed as

$$
S\left(R_{p}\right)=\sqrt{\sum_{i} \sum_{j} \sigma_{i j}}
$$

The amount of risk is defined using $S\left(R_{p}\right)$ of Eq. (2). In this research, using an arbitrary constant $a$, we define the amount of risk $Q$ using the standard deviation $S\left(R_{p}\right)$ of a portfolio as

$$
Q=a S\left(R_{p}\right)
$$

Constant $a$ can be determined using a value at risk (VaR) approach. VaR is a risk index which shows the maximum amount of a potential loss as statistically determined for a fixed confidence interval when financial assets are held for a fixed period. If we assume that the returns from each contract follow a normal distribution for an equipment-providing service, and the period of possession is fixed, constant $a$ can be determined by setting up a confidence interval. An equipment provider should ensure that the amount of risk $Q$ associated with that contract does not exceed the permitted amount of potential loss.

\section{Pricing on a Portfolio Basis}

Because of diversification, the total risk is less than the simple sum of the risk of each contract. Denoting the standard deviation of the return of each contract as $\sigma_{i}$, we can express the effectiveness of diversified investment as

$$
S\left(R_{p}\right)<\sum_{i} \sigma_{i}
$$

Given the lower risk that the provider is exposed to, the pricing of a contract can be reduced. By accurately calculating the risk, we can determine the minimum value of, for example, a service contract.

Our proposed pricing method and the conventional pricing method are compared in Figure 2. In the past each risk premium was based on the risk of the contract, and the price was determined by adding an appropriate risk premium to the cost of providing the service. However, since the total risk that an equipment provider is exposed to depends also on the effect of diversification, each contract price can reflect the saving achieved through diversification. When the risk associated with a contract is expressed as $a_{i} \sigma_{i}$ using the arbitrary constants $a_{i}$ and standard deviation $\sigma_{i}$, the risk premium $P(i)$ for service $i$ is expressed by the following formula based on the amount of portfolio risk $Q$.

$$
P(i)=Q \frac{a_{i} \sigma_{i}}{\sum a_{i} \sigma_{i}}
$$




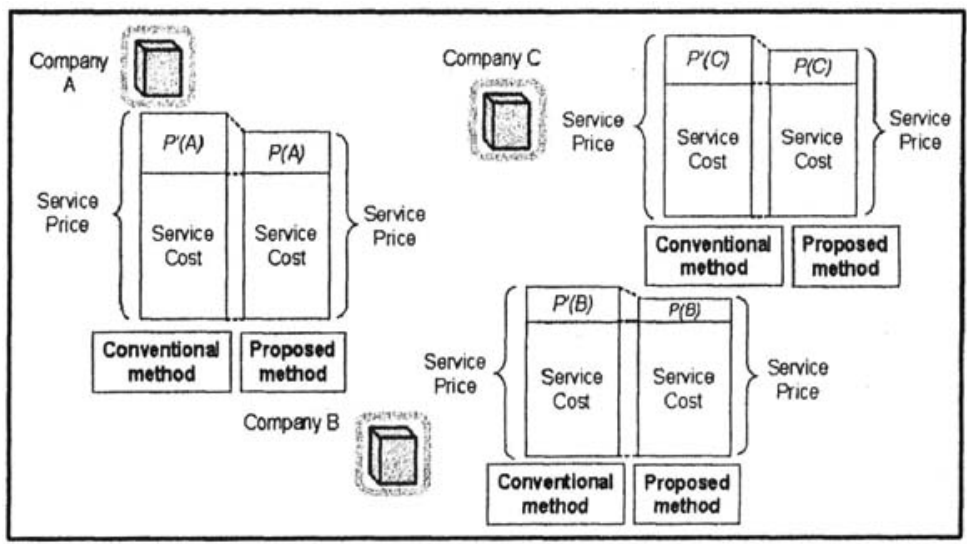

Figure 2. Service Price

Here, to take into account the amount of risk for each contract, $P(i)$ is calculated based on a proportional division of the sum total of risk from all contracts. A lower service price can be offered during contract negotiation based on this $P(i)$.

\section{Verification}

We offer our clients one example of the equipment-providing service. We applied our proposed approach based on a simulation using the charge data from our service to verify the validity of this approach. $P(i)$ was computed using data from the actual service period. The charge data used for verification (Figure 3) was obtained from four services over seven months. The calculated monthly risk premium $P^{\prime}(i)=a_{i} \sigma_{i}$ and $P(i)$ are compared in Table 1 .

We obtained $\sum a_{i} \sigma_{i}=2,106$ and $Q=1,638$. The proposed method thus reduced the conventional risk premium by $22.2 \%$, showing that this approach justifies reducing the contract price. We expect the number of services to increase in the future. Therefore, the effect of diversification within the service

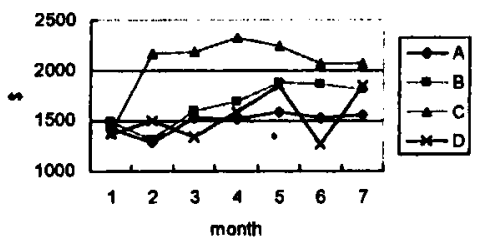

Figure 3. Charge Data 
Table 1. Risk Premium

\begin{tabular}{|c|r|r|}
\hline service & conventional method $\left(a_{i} \sigma_{i}\right)$ & proposed method $(P(i))$ \\
\hline A & 347 & 270 \\
\hline B & 563 & 438 \\
\hline C & 900 & 700 \\
\hline D & 296 & 230 \\
\hline Sum & 2106 & 1638 \\
\hline
\end{tabular}

portfolio will become more significant, enabling further reductions in the risk premium that is charged.

\section{Conclusion}

\section{Summary}

We have shown that an equipment provider can reduce its share of operating risk by providing services to many users in various industries and regions of operation through diversification. By taking an approach where each equipment provider is assumed to hold a portfolio of contracts, we have shown how the total risk a provider is exposed to can be computed. Moreover, we have shown how the pricing of a service contract can be lowered by taking into account the risk reduction achieved through a diversified portfolio approach. We have verified the validity of this approach by simulating its application based on data from the equipment-providing service provided by our company.

\section{Future study}

If the returns from new services are weakly or negatively correlated with those from current services, further reduction in the portfolio risk will be possible. Although the present risk premium in contract pricing reflects a proportional division of the risk taken on by the provider, taking into consideration the correlation between the returns from each service and those from other services will enable more suitable pricing with regard to overall risk. In the future, we will work towards developing specific methods for doing this.

\section{References}

[WB99] R. Wise and P. Baumgartner, "Go Downstream: The New Profit Imperative in Manufacturing," Harvard Business Review, Vol. 77, no. 5, pp. 133-141, 1999.

[Ben89] S. Benninga, NUMERICAL TECHNIQUE IN FINANCE. (MIT Press, 1989).

[GSO1] G. Grimmett and D. Stirzaker, Probability and Random Processes. (Third ed.. Oxford University Press, 2001). 